\title{
Description of a new member of the family Erysipelotrichaceae: Dakotella fusiforme gen. nov., sp. nov., isolated from healthy human feces
}

\author{
Sudeep Ghimire ${ }^{1}$, Supapit Wongkuna ${ }^{1}$, Joy Scaria ${ }^{\text {Corresp. } 1}$ \\ ${ }^{1}$ Department of Veterinary and Biomedical Sciences, South Dakota State University, Brookings, South Dakota, United States \\ Corresponding Author: Joy Scaria \\ Email address: joy.scaria@sdstate.edu
}

A Gram-positive, non-motile, rod-shaped facultative anaerobic bacterial strain $\mathrm{SG} 502^{\top}$ was isolated from healthy human fecal samples in Brookings, SD, USA. The comparison of the $16 \mathrm{~S}$ rRNA gene placed the strain within the family Erysipelotrichaceae. Within this family,

Clostridium innocuum ATCC $14501^{\top}$, Longicatena caecimuris strain PG-426-CC-2,

Eubacterium dolichum DSM $3991^{\top}$ and E. tortuosum DSM $3987^{\top}$ (=ATCC $25548^{\top}$ ) were its closest taxa with 95.28\%, 94.17\%, 93.25\%, and 92.75\% 16S rRNA sequence identities

respectively. The strain SG502 ${ }^{\top}$ placed itself close to $C$. innocuum in the $16 \mathrm{~S}$ rRNA phylogeny. The members of genus Clostridium within family Erysipelotrichaceae was proposed to be reassigned to genus Erysipelatoclostridium to resolve the misclassification of genus Clostridium. Therefore, $C$. innocuum was also classified into this genus temporarily with the need to reclassify it in the future because of its difference in genomic properties. Similarly, genome sequencing of the strain and comparison with its $16 \mathrm{~S}$ phylogenetic members and proposed members of the genus Erysipelatoclostridium, SG502 ${ }^{\top}$ warranted a separate genus even though its $16 \mathrm{~S}$ rRNA similarity was $>95 \%$ when comapred to $C$. innocuum. The strain was $71.8 \%$ similar at ANI, 19.8\% [17.4-22.2\%] at $\mathrm{dDDH}$ and $69.65 \%$ similar at AAl to its closest neighbor $C$. innocuum. The genome size was nearly $2,683,792 \mathrm{bp}$ with $32.88 \mathrm{~mol} \% \mathrm{G}+\mathrm{C}$ content, which is about half the size of $C$. innocuum genome and the $\mathrm{G}+\mathrm{C}$ content revealed 10 mol\% difference. Phenotypically, the optimal growth temperature and $\mathrm{pH}$ for the strain $\mathrm{SG} 502^{\top}$ were $37^{\circ} \mathrm{C}$ and 7.0 respectively. Acetate was the major short-chain fatty acid product of the strain when grown in BHI-M medium. The major cellular fatty acids produced were $C_{18: 1} \omega 9 c, C_{18: 0}$ and $C_{16: 0}$. Thus, based on the polyphasic analysis, for the type strain $\mathrm{SG}_{502}^{\top}\left(=\mathrm{DSM} 107282^{\top}=\operatorname{CCOS} 1889^{\top}\right)$, the name Dakotella fusiforme gen. nov., sp. nov., is proposed. 
1 Description of a new member of the family Erysipelotrichaceae: Dakotella fusiforme gen.

2 nov., sp. nov., isolated from healthy human feces

3 Sudeep Ghimire ${ }^{1}$, Supapit Wongkuna ${ }^{1,}$ and Joy Scaria ${ }^{1 *}$

4 1Department of Veterinary and Biomedical Sciences, South Dakota State University,

5 Brookings, SD, USA.

6

$7 \quad *$ Address correspondence to: Joy Scaria

8 Email: joyscaria@gmail.com

9

10

11

12

13

14

15

16

17

18

19

20

21

22

23

24

Peer] reviewing PDF | (2019:11:43234:1:1:NEW 17 Aug 2020) 


\section{ABSTRACT}

A Gram-positive, non-motile, rod-shaped facultative anaerobic bacterial strain $\mathrm{SG} 502^{\mathrm{T}}$ was isolated from healthy human fecal samples in Brookings, SD, USA. The comparison of the 16S rRNA gene placed the strain within the family Erysipelotrichaceae. Within this family,

Clostridium innocuum ATCC 14501 ${ }^{\mathrm{T}}$, Longicatena caecimuris strain PG-426-CC-2,

Eubacterium dolichum DSM $3991^{\mathrm{T}}$ and E. tortuosum DSM $3987^{\mathrm{T}}\left(=\mathrm{ATCC} 25548^{\mathrm{T}}\right)$ were its closest taxa with $95.28 \%, 94.17 \%, 93.25 \%$, and 92.75\% 16S rRNA sequence identities respectively. The strain $\mathrm{SG} 502^{\mathrm{T}}$ placed itself close to $C$. innocuum in the $16 \mathrm{~S}$ rRNA phylogeny. The members of genus Clostridium within family Erysipelotrichaceae was proposed to be reassigned to genus Erysipelatoclostridium to resolve the misclassification of genus Clostridium. Therefore, C. innocuum was also classified into this genus temporarily with the need to reclassify it in the future because of its difference in genomic properties. Similarly, genome sequencing of the strain and comparison with its $16 \mathrm{~S}$ phylogenetic members and proposed members of the genus Erysipelatoclostridium, $\mathrm{SG} 502^{\mathrm{T}}$ warranted a separate genus even though its $16 \mathrm{~S}$ rRNA similarity was $>95 \%$ when compared to $C$. innocuum. The strain was $71.8 \%$ similar at ANI, 19.8\% [17.4-22.2\%] at $\mathrm{dDDH}$ and $69.65 \%$ similar at AAI to its closest neighbor C. innocuum.

43 The draft genome size of SG502 ${ }^{\mathrm{T}}$ was $2,683,792 \mathrm{bp}$ with $32.88 \mathrm{~mol} \% \mathrm{G}+\mathrm{C}$ content, which is about half the size of $C$. innocuum genome and the $\mathrm{G}+\mathrm{C}$ content revealed $10 \mathrm{~mol} \%$ difference. Phenotypically, the optimal growth temperature and $\mathrm{pH}$ for the strain $\mathrm{SG} 502^{\mathrm{T}}$ were $37^{\circ} \mathrm{C}$ and 7.0 respectively. Acetate was the major short-chain fatty acid product of the strain when grown in

47 BHI-M medium. The major cellular fatty acids produced were $C_{18: 1} \omega 9 \mathrm{c}, \mathrm{C}_{18: 0}$ and $\mathrm{C}_{16: 0}$. Thus, 
48 based on the polyphasic analysis, for the type strain SG502 $\left(=\mathrm{DSM} 107282^{\mathrm{T}}=\operatorname{CCOS} 1889^{\mathrm{T}}\right)$,

49 the name Dakotella fusiforme gen. nov., sp. nov., is proposed.

50 Key words: Dakotella fusiforme, new genus, new species, gut microbiota, taxonomy, 51 microbiome, culturomics

\section{1. INTRODUCTION}

53

54

55

56

57

58

59

60

61

62

63

64

65

66

67

68

70

69 Dubosiella, Eggerthia, Erysipelothrix, Faecalibaculum, Faecalicoccus, Faecalitalea,

The members of family Erysipelotrichaceae have been isolated from the intestinal tracts of mammals (Alcaide et al. 2012; Greiner \& Backhed 2011; Han et al. 2011) and insects (Egert et al. 2003) and are associated with host metabolism and inflammatory diseases (Cox et al. 2014; Kaakoush 2015). Although metagenome analysis of gut microbiome have revealed the composition and function of the microbiome in the intestine, only a few cultured species available from this family and their function in the gut ecosystem is not yet well understood (Kaakoush 2015).

The family Erysipelotrichaceae was originally described by Verbarg et al (Verbarg et al. 2004).

The members of this family includes Gram-positive, filamentous rods and were originally described as facultative anaerobes but later amended by Tegtmeier et al. (Tegtmeier et al. 2016) to include obligate anaerobes. The members of this family belonged to Clostridial Cluster XVI that consists of three major species; Clostridium innocuum, Eubacterium biforme and Streptococcus pleomorphus (Collins et al. 1994). According to the updated LPSN list of valid 67 bacteria (http://www.bacterio.net), current members of this family includes the following genera: 68 Allobaculum, Breznakia, Bulleidia, Catenibacterium, Canteisphaera, Coprobacillus, Dielma, 70 Holdemania, Kandleria, Longibacculum, Longicatena, Solobacterium, and Turicibacter. 
71 Members of this family have low $-\mathrm{G}+\mathrm{C}$ content and were previously recognized as the "walled

72 relatives" of mycoplasma (Weisburg et al. 1989) and later classified under Clostridial cluster XVI

73 (Collins et al. 1994). With major changes in the taxonomy of Erysipelotrichaceae, recently some

74 members have been reclassified into new families Coprobacillaceae (Collins et al. 1994) and

75 Turicibacteraceae (Verbarg et al. 2014) but the placement of cluster XVI is still debated. A few

76 species related to Clostridium and Eubacterium are also included within Erysipelotrichaceae based

77 on the 16S rRNA gene sequence similarity and are considered as misclassified (Verbarg et al.

78 2014). For the proper classification of these misclassified members of genus Clostridium, different

79 genus names were proposed by Yutin and Galperin in 2013 where C. innocuum along with $C$.

80 cocleatum, C. saccharogumia and C. spiroforme were proposed to be reassigned to a new genus

81 Erysipelatoclostridium. As, C. innocuum was found to be more distantly related to other members

82 inside Erysipelatoclostridum genus, they also highlighted the need of future reclassification of $C$.

83 innocuum (Yutin \& Galperin 2013).

The present study describes the isolation, physiology, and genomic characterization of a new member of the family Erysipelotrichaceae isolated from healthy human feces. Within the family Erysipelotrichaceae, strain SG502 ${ }^{\mathrm{T}}$ clustered within clostridial cluster XVI. Also, the strain SG502 ${ }^{\mathrm{T}}$ showed less than $97 \%$ 16S rRNA gene sequence similarity towards its nearest phylogenetic neighbor $C$. innocuum ATCC $14501^{\mathrm{T}}$. Therefore, we performed in vitro phenotypic major differences in the genomic and phenotypic characteristics of the strain even though its $16 \mathrm{~S}$ 
93 and species for this strain and propose designating $\mathrm{SG} 502^{\mathrm{T}}$ as Dakotella fusiforme gen. nov., sp.

94 nov within the family Erysipelotrichaceae.

95

\section{MATERIALS AND METHODS}

\subsection{Bacterial isolation and culture condition}

98

99

100

101

102

103

104

105

106

107

108

109

110

111

112

113

114

The strain was isolated from healthy human fecal sample as part of a culturomics study. The collection of the human fecal samples were done with the approval of the Institutional review board (approval \#IRB-1709018-EXP) at South Dakota State University, Brookings SD. After transferring the fresh fecal samples into the anaerobic chamber ( $85 \%$ nitrogen, $10 \%$ hydrogen and 5\% carbon dioxide) within 10 minutes of voiding, the sample was diluted 10 times with anaerobic PBS and stored with $18 \%$ DMSO in $-80^{\circ} \mathrm{C}$. The sample was cultured in modified BHI medium (BHI-M) containing 37g/L of BHI, $5 \mathrm{~g} / \mathrm{L}$ of yeast extract, $1 \mathrm{ml}$ of $1 \mathrm{mg} / \mathrm{mL}$ menadione, $0.3 \mathrm{~g}$ of L-cysteine, $1 \mathrm{~mL}$ of $0.25 \mathrm{mg} / \mathrm{L}$ of resazurin, $1 \mathrm{~mL}$ of $0.5 \mathrm{mg} / \mathrm{mL}$ hemin, $10 \mathrm{~mL}$ of vitamin and mineral mixture, $1.7 \mathrm{~mL}$ of $30 \mathrm{mM}$ acetic acid, $2 \mathrm{~mL}$ of $8 \mathrm{mM}$ propionic acid, $2 \mathrm{~mL}$ of $4 \mathrm{mM}$ butyric acid, $100 \mu \mathrm{l}$ of $1 \mathrm{mM}$ isovaleric acid, and $1 \%$ pectin and inulin. After isolation, the strain was subjected to MALDI-ToF (Bruker, Germany). Since MALDI-ToF did not identify a species, 16S rRNA gene sequencing was performed for species identification.

\subsection{Phenotypic and chemotaxonomic characterization}

For morphological, physiological and biochemical characterization, the strain was cultivated in BHI-M medium in anaerobic conditions at $37^{\circ} \mathrm{C}$ at $\mathrm{pH} 6.8 \pm 0.2$. Colony characteristics were determined after streaking the strain on BHI-M agar plates followed by 48 hours of anaerobic 
115 incubation. Gram staining was performed using a Gram staining kit (BD Difco) according to the

116 manufacturer's protocol. During the exponential growth of the bacterium, cell morphology and

117 flagellation was examined under scanning electron microscopy (SEM). SG502 ${ }^{\mathrm{T}}$ was grown

118 separately in aerobic and anaerobic conditions to determine the aerotolerance. Further, the strain

119 was grown at $4,20,30,40$ and $55^{\circ} \mathrm{C}$ to determine the range of growth under anaerobic conditions.

120 The BHI-M media was adjusted to $\mathrm{pH}$ levels between 4 and 9 with $0.1 \mathrm{~N} \mathrm{HCl}$ and $0.1 \mathrm{~N} \mathrm{NaOH}$ to

121 determine the growth of the strain at different $\mathrm{pH}$ levels. BHI-M medium was supplemented with

122 triphenyltetrazolium chloride (TTC) (Shields \& Cathcart 2011

123 ) to determine the motility of the strain.

124

125 The phenotypic and biochemical characterizations were performed using AN MicroPlate (Biolog)

126 and API ZYM (bioMerieux) according to the manufacturer's instructions. Also, after growing the

127 strain SG502 ${ }^{\mathrm{T}}$ and ATCC $14501^{\mathrm{T}}$ in BHI-M medium at $37^{\circ} \mathrm{C}$ for 24 hours, cells were harvested

128 for cellular fatty acid analysis. Fatty acids were extracted, purified, methylated, identified and 129 analyzed using GC (Agilent 7890A) according to manufacturer's instructions (MIDI) (Sasser 130 1990). Further, short-chain fatty acid (SCFA) production was determined using gas 131 chromatography after cells were grown in BHI-M medium. For SCFA estimation, $800 \mu 1$ of the 132 bacterial culture was collected and $160 \mu \mathrm{l}$ of freshly prepared $25 \%$ meta-phosphoric acid (w/v) 133 was added before freezing to $-80^{\circ} \mathrm{C}$. The sample were thawed and centrifuged at $>20,000 \times \mathrm{g}$ for 30 $134 \mathrm{~min}$ before injecting $600 \mu \mathrm{l}$ of the supernatant into the TRACE1310 GC system (ThermoScientific, 135 USA). 


\section{$137 \quad 2.3$ Phylogenetic analysis}

138 Genomics DNA from the strain was isolated using E.Z.N.A bacterial DNA isolation kit (Omega

139 Biotek) following the manufacturer's instructions. The 16S rRNA gene was amplified using 140 universal primer set 27F (5'- AGAGTTTGATCMTGGCTCAG-3') and 1492R (5'141 ACCTTGTTACGACTT- 3') and sequenced using a Sanger sequencing chemistry (ABI 3730XL; 142 Applied Biosystems). The sequences were assembled using Genious 10.2.3. The nearly complete 143 16S rRNA gene sequence obtained was used for a similarity search in EzTaxon-e program 144 (http://www.ezbiocloud.net/) for the valid taxonomic names. The bacterial species that closely 145 resembled the query sequences were then used for alignment and phylogenetic analysis in 146 MEGAX software (Kumar et al. 2016). Initially, the sequences were aligned using MUSCLE 147 (Edgar 2004) and the Neighbor Joining method (Saitou \& Nei 1987) was used to reconstruct the 148 phylogenetic tree employing Kimura 2-parameter model (Kimura 1980) with 1000 bootstraps. 149 Phylogenetic trees were also constructed using maximum-likelihood (Felsenstein 1981)and 150 minimum evolution methods (Rzhetsky. A. \& M. 1992). Clostridium butyricum ATCC 19398 151 was used as an out-group.

\subsection{Genomic features and comparison}

154 For the whole genome sequencing of SG502 ${ }^{\mathrm{T}}$, we used $0.3 \mathrm{ng}$ of the genomic DNA for library 155 preparation. Library was sequenced on an Illumina MiSeq using 2x 250 paired-end V2 chemistry.

156 Genome was assembled from raw fastq files using Unicycler which builds an initial assembly 157 graph from short reads using the de novo assembler SPAdes3.11.1 (Bankevich et al. 2012). Quality 158 assessment for the assemblies was performed using QUAST (Gurevich et al. 2013). Genome 
159 annotation was performed using Prokka 1.13 (Seemann 2014). The genome of SG502 ${ }^{\mathrm{T}}$ was

160 visualized using DNAplotter (Carver et al. 2009).

161

162 We compared the genome of $\mathrm{SG} 502^{\mathrm{T}}$ to that of $16 \mathrm{~S}$-phylogeny of closely related species $C$.

163 innocuum DSM 1286 ${ }^{\mathrm{T}}$, Longicatena caecimuris DSM 29481 ${ }^{\mathrm{T}}$, Eubacterium dolichum DSM

$1643991^{\mathrm{T}}$, Faecalicoccus pleomorphus DSM 20574 ${ }^{\mathrm{T}}$, Faecalitalea cylindroides ATCC 27803 ${ }^{\mathrm{T}}$,

165 Holdemanella biformis DSM 3989 ${ }^{\mathrm{T}}$ and Dielma fastidiosa DSM 26099 . In addition, we

166 compared SG502 ${ }^{\mathrm{T}}$ with the proposed members of the genus Erysipelatoclostridium, C. clocleatum

167 DSM $1551^{\mathrm{T}}$, C. ramosum DSM $1402^{\mathrm{T}}$, C. saccharogumia DSM $17460^{\mathrm{T}}$ and C. spiroforme DSM

$1681552^{\mathrm{T}}$. We used the average nucleotide identity (OrthoANI) (Lee et al. 2016) and digital DDH

169 (Meier-Kolthoff \& Goker 2019) for calculating phylogenomic similarity. We also performed

170 average amino acid identity (AAI) using AAI calculator (Konstantinidis \& Tiedje 2005) to

171 determine protein level genome differences.

173 3. RESULTS

174 The SG502 ${ }^{\mathrm{T}}$ strain was isolated from the healthy human fecal sample during the culturomics study

175 of the human gut microbiota. The colonies of the strain appeared white, smooth and convex with 176 entire edges. The cells were initially subjected to MALDI-ToF MS (Figure 1A) which revealed 177 the score $<1.70$ suggesting no identification. Thus, further phenotypic characterization and genetic 178 based methods were employed for identification of the strain. 
180 Morphologically, individual cells of the strain appeared to be gram-positive rods. The cell was 181 observed to be slender with tapering ends with $1.5 \times 0.35 \mu \mathrm{m}$ in dimensions (Figure $1 \mathrm{~B}$ and Table

182 1) under SEM. No flagella were observed under SEM suggesting its non-motile nature which was 183 also validated by TTC assay. The strain also lacked endospores, similar to what has been 184 previously reported for the members of Erysipelotrichaceae (Verbarg et al. 2004). The strain grew 185 in a $\mathrm{pH}$ range of 6.0-7.5 with optimal growth at $\mathrm{pH}$ 7.0. It could grow anaerobically over the 186 temperature range of $25-45^{\circ} \mathrm{C}$ with optimal growth at $37^{\circ} \mathrm{C}$. The strain grew well in BHI-M under 187 anaerobic conditions but under aerobic conditions, the growth was comparatively lower and slow 188 confirming that the strain was a facultative anaerobe. Based on the results obtained from a carbon source utilization test (Biolog AN plate), the strain utilizes glucose, sorbitol, maltose, arbutin, D-

190 fructose, L-fucose, palatinose, dextrin, turanose, D-trehalose, L-rhamnose, uridine, pyruvic acid 191 methyl ester, pyruvic acid, 3-methyl-D-glucose, gentiobiose, maltotriose, ducitol, L192 phenylalanine, $\alpha$-ketovaleric acid, N-acetyl-D-glucosamine, N-acetyl- $\beta$-D-mannosamine, 193 cellobiose, $\alpha$-ketobutyric acid, D-galacturonic acid and N-acetyl-D-glucosamine. Also, SG502 194 assimilated sorbitol and maltose which were not utilized by its closest neighbor $C$. innocuum ATCC $14501^{\mathrm{T}}$. Furthermore, SG502 ${ }^{\mathrm{T}}$ was unable to utilize sucrose, salicin, mannitol, lactose, and 196 raffinose when compared to $C$. innocuum. Positive enzymatic activities for leucine arylamidase, 197 cystine arylamidase, $\alpha$-chymotripsin and acid phosphates were observed for C. innocuum 198 differentiating it from SG502 ${ }^{\mathrm{T}}$. Detailed phenotypic and biochemical characteristics of the strain are presented in Table 1 . Also, the major fatty acids content identified were $\mathrm{C}_{18: 1} \omega 9 \mathrm{c}(29.82 \%)$, $200 \mathrm{C}_{18: 0}(22.55 \%)$ and $\mathrm{C} 16: 0(14.7 \%)$ compared to $C$. innocuum ATCC $14501^{\mathrm{T}}$ with $\mathrm{C}_{18: 1} \omega 9 \mathrm{c}$ 201 (14.64\%), $\mathrm{C}_{18: 0}(10.56 \%)$ and C16:0 (23.7\%) (Table 2). The detailed comparison of the fatty acids 202 in SG502 ${ }^{\mathrm{T}}$ along with C. innocuum $14501^{\mathrm{T}}$ and E. dolichum DSM 3991 ${ }^{\mathrm{T}}$ is given in Table 2. 
203 Additionally, the major SCFAs metabolite identified for SG502 ${ }^{\mathrm{T}}$ was acetate in BHI-M medium.

204 Low but detectable amounts of propionate and butyrate were produced by the strain SG502 ${ }^{\mathrm{T}}$. The

205 utilization of such broad substrates and production of SCFAs can be ecologically effective trait

206 against pathogen colonization in the gut.

As the strain was not identified using MALDI-ToF, 16S rRNA sequence was amplified to obtain a continuous stretch of 1338 bp gene which was searched against the Eztaxon 16S rRNA gene database for identification. The closest species identified were all from the Erysipelotrichaceae family that included C. innocuum ATCC $14501^{\mathrm{T}}$, L. caecimuris strain PG-426-CC-2, E. dolichum DSM $3991^{\mathrm{T}}$ and E. tortuosum ATCC $25548^{\mathrm{T}}$ with $95.28 \%, 94.17 \%, 93.25 \%$, and 92.75\% sequence identities respectively. Currently, the cut off for the species and genus level classification of the bacteria based on $16 \mathrm{~S}$ rRNA gene is $<98.7 \%$ (E. \& J. 2006) and <94.5\% identity (Yarza et al. 2014) respectively. Thus, the strain $\mathrm{SG502}{ }^{\mathrm{T}}$ and C. innocuum were suggested to fall within same genus but different species. The phylogenetic analysis also revealed that the isolate belonged to Erysipelotrichaceae family where the strain $\mathrm{SG} 502^{\mathrm{T}}$ was closely associated to C. innoccum ATCC $14501^{\mathrm{T}}$ but further from L. caecimuris strain PG-426-

219 CC-2, E. dolichum DSM $3991^{\mathrm{T}}$ and E. tortuosum ATCC $25548^{\mathrm{T}}$ which altogether formed a larger clade (Figure 2). The separation of these four species from the strain SG502 ${ }^{\mathrm{T}}$ did not depend on the phylogenetic algorithm and was supported by an $100 \%$ bootstrap value. To further differentiate the strain, we sequenced the whole genome of the strain and is visualized in Figure 3. The draft genome of the strain $\mathrm{SG} 502^{\mathrm{T}}$ was $2,683,792 \mathrm{bp}$ with $32.88 \mathrm{~mol} \% \mathrm{G}+\mathrm{C}$ content. The largest contig was of $154,144 \mathrm{bp}$ and $\mathrm{N}_{50}$ was 52,214 . The total number of predicted coding sequences, tRNAs, rRNAs, and tmRNAs was 2654, 49, 2 and 1 respectively. 
227 C. innocuum was the nearest neighbor of $\mathrm{SG}^{2} 02^{\mathrm{T}}$ based on $16 \mathrm{~S}$ rRNA phylogeny. C. innocuum

228 along with C. cocleatum, C. saccharogumia, C. ramosum, and C. spiroforme were suggested to 229 be reclassified previously into genus Erysipelatoclostridium with $C$. innocuum needing further 230 reclassification (Yutin \& Galperin 2013). Therefore, we checked for the $16 \mathrm{~S}$ identity of SG502 231 with the other members of this proposed genera C. cocleatum, C. saccharogumia, C. ramosum, 232 and C. spiroforme in NCBI. These species were found to be $84.45 \%, 84.49 \%, 85.10 \%$ and $23385.014 \%$ identical respectively which demonstrated that SG502 ${ }^{\mathrm{T}}$ should not be placed into same 234 genera with these species. We also compared the genomic properties of the strain with its $16 \mathrm{~S}$ 235 rRNA based phylogenetic neighbors along with $C$. innocuum and the members of formerly 236 proposed genus Erysipelatoclostridium, C. cocleatum, C. saccharogumia, C. ramosum, and $C$.

237 spiroforme. The genomic sizes and $\mathrm{G}+\mathrm{C}$ content of the members of the neighbors of the strain 238 were found to vary as shown in Table 3. C. innocuum was 4,772,018 bp in length with 43.4 $239 \mathrm{~mol} \% \mathrm{G}+\mathrm{C}$ content, while for SG502 ${ }^{\mathrm{T}}$, genome length was 2, 683,792 bp with $32.88 \mathrm{~mol} \%$ $240 \mathrm{G}+\mathrm{C}$ content. The genome sizes and $\mathrm{G}+\mathrm{C}$ content of the neighboring species were highly 241 variable compared to SG502 ${ }^{\mathrm{T}}$ (Table 3). Because of such high differences in the genome 242 properties of SG502 ${ }^{\mathrm{T}}$, we performed further comparison for classifying $\mathrm{SG} 502^{\mathrm{T}}$ as a novel genus. 243 Hence, the genome of the strain was compared to its neighbors using OrthoANI as shown in 244 Figure 4. The strain SG502 ${ }^{\mathrm{T}}$ was $71.8 \%$ similar to its nearest neighbor C. innocuum and had 245 lower similarities with other neighbors. (Figure 4A, 4B). The proposed cut-off for OrthoANI for 246 a new species is 95-96\% (Kim et al. 2014) (Lee et al. 2016). The dDDH was only 19.8\%

247 between $\mathrm{SG} 502^{\mathrm{T}}$ and C. innocuum (Table 4). One of the major methods to demarcate the genus 248 is to calculate average amino acid identity (AAI) between the genomes with the possibility of 
249 novel genus if the AAI values are in the range of 65-72\% (Konstantinidis \& Tiedje 2007). The

250 strain SG502 ${ }^{\mathrm{T}}$ showed highest AAI with C. innocuum (69.65\%) followed by L. caecimuris

$251(63.45 \%)$ and E. dolichum (63.02\%) (Figure 5) supporting the designation of strain SG502 ${ }^{\mathrm{T}}$ in a 252 novel genus.

\section{DISCUSSION}

255

256

257

258

259

260

261

262

263

264

265

266

267

268

269

270

Recently, next generation sequencing and high-throughput culturing methods has been employed for large scale culture of the unknown gut microbiota. This new approach termed as "culturomics" has evolved as a tool to culture previously uncultured bacteria (Browne et al. 2016; Lagier et al. 2016). However, such culture independent studies have also highlighted that the diverse population of gut bacteria are yet to be cultivated (Almeida et al. 2019; Lagier et al. 2012). The pure culture of the bacteria is essential to elucidate the role of these organisms in health and diseases for both experimental model and therapeutics purposes (Daillere et al. 2016; Kobyliak et al. 2016; Vetizou et al. 2015). In this study, we report the culturing and characterization of a previously uncultured bacterium SG502 ${ }^{\mathrm{T}}$ from the healthy human fecal samples that belongs to a new genus and species. Also, we employed taxono-genomics approach (Fournier \& Drancourt 2015) to determine the phenotypic and genetic properties of the taxon.

$16 \mathrm{~S}$ rRNA based gene sequence homology is the widely used method to determine the novelty of the prokaryotic organism with varying threshold values at distinct taxonomic levels (Clarridge 2004; Kim et al. 2014). Therefore, we performed the 16SrRNA based phylogenetic analysis of the strain SG502 ${ }^{\mathrm{T}}$ which showed it as a member of Erysipelotrichaceae family. Under this 
271 family, it clustered together with Clostridium innoccum, Longicatena caecimuris, Eubacterium

272 dolichum and Eubacterium tortuosum with C. innocuum as a closest member. C. innocuum along

273 with other members of misclassified Clostridia under Erysipelotrichaceae family were proposed

274 to be reclassified into gen. nov. Erysipeloclostridium. The members of this proposed genus

275 Erysipelatoclostridium are gram positive, nonmotile, obligately anaerobic straight or helically

276 curved rods which rarely forms spores. The $\mathrm{G}+\mathrm{C}$ content is lower and varies from $27-33 \mathrm{~mol} \%$

277 (Yutin \& Galperin 2013). However, C. innocuum was identified to be a distantly related member

278 of Erysipelatoclostridium with higher $\mathrm{G}+\mathrm{C}$ content of $43-44 \%$ with need of reclassification

279 (Yutin \& Galperin 2013). In this context, we also searched for the 16S based identity of the

280 strain SG502 ${ }^{\mathrm{T}}$ with the proposed members of genus Erysipelatoclostridium. Nevertheless, the

281 proposed members of genus Erysipelatoclostridium were $<86 \%$ similar at 16S sequence level,

282 suggesting the uniqueness of SG502 ${ }^{\mathrm{T}}$.

Phenotypically, $\mathrm{SG} 502^{\mathrm{T}}$ revealed several differences in carbon sources utilization, enzymatic activity and fatty acid when compared to its phylogenetic neighbors (Table 1 and Table 2). In addition, whole genome sequence comparison revealed its distinctiveness with respect to $16 \mathrm{~S}$ phylogenetic members and the proposed members of Erysipelatoclostridium genus (Table 3 and as high as $71.54 \%$ similarity with $L$. caecimuris DSM $29481^{\mathrm{T}}$. Also, the genome of SG502 ${ }^{\mathrm{T}}$ was only $82.21 \%$ similar with C. cocleatum DSM $1551^{\mathrm{T}}$ which is a member of Erysipelatoclostridium genus (Figure 4). Major differences were evident in dDDH and amino acid composition comparison as well (Table 4, Figure 5). Finally, the genome size of the nearest

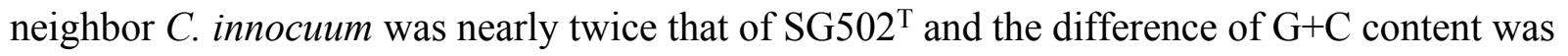


294 comparatively high (>10 mol\%) suggesting that the strain is not close to C. innocuum genetically

295 which means that $\mathrm{SG} 502^{\mathrm{T}}$ require the placement in a separate genus.

\section{CONCLUSION}

298

Despite $95.15 \% 16 \mathrm{~S}$ rRNA similarity of $\mathrm{SG} 502^{\mathrm{T}}$ with its nearest neighbor $C$. innocuum, the differences in its physiological, biochemical, and whole genome sequence suggest its placement in a novel genus. Hence, we propose creation of a novel genus Dakotella under family Erysipelotrichaceae and classification of $\mathrm{SG} 502^{\mathrm{T}}$ under new genus Dakotella as Dakotella fusiforme SG502 $\mathrm{T}$.

\section{DESCRIPTION OF Dakotella gen. nov.}

Dakotella (Da.ko.tel'la. M.L. dimin. ending -ella; N.L. fem. n. Dakotella, from the place of isolation, State of South Dakota, USA).

The type strain is elongated spindle shaped. The closest phylogenetic neighbor is $C$. innocuum ATCC $14501^{\mathrm{T}}$ with corresponding $\mathrm{dDDH}$ of $19.8 \%$. The relative genomic $\mathrm{G}+\mathrm{C}$ difference with C. innocuum is $10.48 \mathrm{~mol} \%$. The OrthoANI of the isolate and the type species C. innocuum is 71.8\%. E. dolichum DSM $3991^{\mathrm{T}}$ and Longicatena caecimuris DSM $20574^{\mathrm{T}}$ are distantly related with OrthoANI of $70.85 \%$ and $71.84 \%$ and $\mathrm{dDDH}$ of only $20.6 \%$ and $20.5 \%$ respectively. The corresponding difference in the $\mathrm{G}+\mathrm{C}$ content is $5.22 \%$ and $4.86 \%$ with E. dolichum $\mathrm{DSM} 3991^{\mathrm{T}}$ and Longicatena caecimuris DSM $20574^{\mathrm{T}}$ respectively. Such differences support the creation of 
314 novel genus to accommodate SG502 ${ }^{\mathrm{T}}$. The $\mathrm{G}+\mathrm{C}$ content of the genomic DNA of the type strain

315 is $32.88 \mathrm{~mol} \%$. The type species is Dakotella fusiforme.

\section{DESCRIPTION OF Dakotella fusiforme sp. nov. SG502T ${ }^{\mathrm{T} p .}$ nov.}

The cells of the bacterium are anaerobic, gram-positive non-motile rods. The average size of the cell is $1.5 \times 0.35 \mu \mathrm{m}$. Bacterial colonies on BHI-M agar are white, convex and entire approximately

$0.1 \mathrm{~cm}$ in diameter. The optimum temperature and $\mathrm{pH}$ for the anaerobic growth are $37^{\circ} \mathrm{C}$ and 7.0 respectively. The strain SG502 ${ }^{\mathrm{T}}$ utilizes glucose, sorbitol, maltose, arbutin, D-fructose, L-fucose, palatinose, dextrin, turanose, D-trehalose, L-rhamnose, uridine, pyruvic acid methyl ester, pyruvic acid, 3-methyl-D-glucose, gentiobiose, maltotriose, ducitol, L-phenylalanine, a-ketovaleric acid, N-acetyl-D-glucosamine, N-acetyl-b-D-mannosamine, cellobiose, a-ketobutyric acid, Dgalacturonic acid and N-acetyl-D-glucosamine. Positive enzymatic reactions were observed for while small amounts of propionate and butyrate were also noted. The major cellular fatty acids of

329 the strain $\mathrm{SG} 502^{\mathrm{T}}$ are $\mathrm{C}_{18: 1} \omega 9 \mathrm{c}, \mathrm{C}_{18: 0}$ and $\mathrm{C}_{16: 0 .}$. The type strain, $\mathrm{SG} 502^{\mathrm{T}}\left(=\mathrm{DSM} 107282^{\mathrm{T}}=\mathrm{CCOS}\right.$ $1889^{\mathrm{T}}$ ), was isolated from a healthy human fecal sample. The genomic size of the strain is 2 , $683,792 \mathrm{bp}$ and $\mathrm{G}+\mathrm{C}$ content of the strain $\mathrm{SG} 502^{\mathrm{T}}$ is $32.88 \mathrm{~mol} \%$.

\section{PROTOLOGUE}


334 The GenBank accession number for the 16S rRNA gene sequence of the strain $\mathrm{SG}^{2} 02^{\mathrm{T}}$ is

335 MN266902. The GenBank BioProject ID number for the draft genome sequence of the strain $336 \mathrm{SG502}{ }^{\mathrm{T}}$ is PRJNA494608.

337

338 AUTHOR STATEMENTS

339 Funding information

340 This work was supported by the USDA National Institute of Food and Agriculture,

341 Hatch projects SD00H702-20 and SD00R540-15, and a grant from the South Dakota Governor's

342 Office of Economic Development awarded to Joy Scaria. No additional external funding was

343 received for this study.

344 Acknowledgments

345 The authors would like to thank Electron Microscopy Core Facility at the Bowling Green

346 State University, Ohio, USA for assistance with scanning electron microscopy.

347 Conflicts of interest

348 The authors declare no conflicts of interest.

350 ABBREVIATIONS

351 MALDI-ToF: Matrix Assisted Laser Desorption/Ionization-Time of Flight

352 ANI: Average Nucleotide Identity 


\section{REFERENCES}

355

356

357

358

359

360

361

362

363

364

365

366

367

368

369

370

371

372

373

374

375

376

377

378

379

380

381

382

383

384

385

386

387

388

389

390

391

392

393

394

395

396
Alcaide M, Messina E, Richter M, Bargiela R, Peplies J, Huws SA, Newbold CJ, Golyshin PN, Simon MA, Lopez G, Yakimov MM, and Ferrer M. 2012. Gene sets for utilization of primary and secondary nutrition supplies in the distal gut of endangered Iberian lynx. PLoS One 7:e51521. 10.1371/journal.pone.0051521

Almeida A, Mitchell AL, Boland M, Forster SC, Gloor GB, Tarkowska A, Lawley TD, and Finn RD. 2019. A new genomic blueprint of the human gut microbiota. Nature 568:499-504. 10.1038/s41586-0190965-1

Bankevich A, Nurk S, Antipov D, Gurevich AA, Dvorkin M, Kulikov AS, Lesin VM, Nikolenko SI, Pham S, Prjibelski AD, Pyshkin AV, Sirotkin AV, Vyahhi N, Tesler G, Alekseyev MA, and Pevzner PA. 2012. SPAdes: a new genome assembly algorithm and its applications to single-cell sequencing. $J$ Comput Biol 19:455-477. 10.1089/cmb.2012.0021

Browne HP, Forster SC, Anonye BO, Kumar N, Neville BA, Stares MD, Goulding D, and Lawley TD. 2016. Culturing of 'unculturable' human microbiota reveals novel taxa and extensive sporulation. Nature 533:543-546. 10.1038/nature17645

Carver T, Thomson N, Bleasby A, Berriman M, and Parkhill J. 2009. DNAPlotter: circular and linear interactive genome visualization. Bioinformatics 25:119-120. 10.1093/bioinformatics/btn578

Clarridge JE, 3rd. 2004. Impact of 16S rRNA gene sequence analysis for identification of bacteria on clinical microbiology and infectious diseases. Clin Microbiol Rev 17:840-862, table of contents. 10.1128/CMR.17.4.840-862.2004

Collins MD, Lawson PA, Willems A, Cordoba JJ, Fernandez-Garayzabal J, Garcia P, Cai J, Hippe H, and Farrow JA. 1994. The phylogeny of the genus Clostridium: proposal of five new genera and eleven new species combinations. Int J Syst Bacteriol 44:812-826.

Cox LM, Yamanishi S, Sohn J, Alekseyenko AV, Leung JM, Cho I, Kim SG, Li H, Gao Z, Mahana D, Zarate Rodriguez JG, Rogers AB, Robine N, Loke P, and Blaser MJ. 2014. Altering the intestinal microbiota during a critical developmental window has lasting metabolic consequences. Cell 158:705-721. 10.1016/j.cell.2014.05.052

Daillere R, Vetizou M, Waldschmitt N, Yamazaki T, Isnard C, Poirier-Colame V, Duong CPM, Flament C, Lepage $\mathrm{P}$, Roberti MP, Routy B, Jacquelot N, Apetoh L, Becharef S, Rusakiewicz S, Langella $\mathrm{P}$, Sokol H, Kroemer G, Enot D, Roux A, Eggermont A, Tartour E, Johannes L, Woerther PL, Chachaty E, Soria JC, Golden E, Formenti S, Plebanski M, Madondo M, Rosenstiel P, Raoult D, Cattoir V, Boneca IG, Chamaillard M, and Zitvogel L. 2016. Enterococcus hirae and Barnesiella intestinihominis Facilitate Cyclophosphamide-Induced Therapeutic Immunomodulatory Effects. Immunity 45:931-943. 10.1016/j.immuni.2016.09.009

E. S, and J. E. 2006. Taxonomic parameters revisited: tarnished gold standards. Microbiology Today 33:152-155.

Edgar RC. 2004. MUSCLE: multiple sequence alignment with high accuracy and high throughput. Nucleic Acids Res 32:1792-1797. 10.1093/nar/gkh340

Egert M, Wagner B, Lemke T, Brune A, and Friedrich MW. 2003. Microbial community structure in midgut and hindgut of the humus-feeding larva of Pachnoda ephippiata (Coleoptera: Scarabaeidae). Appl Environ Microbiol 69:6659-6668. 10.1128/aem.69.11.6659-6668.2003

Felsenstein J. 1981. Evolutionary trees from DNA sequences: a maximum likelihood approach. J Mol Evol 17:368-376.

Peer] reviewing PDF | (2019:11:43234:1:1:NEW 17 Aug 2020) 
402

403

404

405

406

407

408

409

410

411

412

413

414

415

416

417

418

419

420

421

422

423

424

425

426

427

428

429

430

431

432

433

434

435

436

437

438

439

440

441

442

443

Fournier PE, and Drancourt M. 2015. New Microbes New Infections promotes modern prokaryotic taxonomy: a new section "TaxonoGenomics: new genomes of microorganisms in humans". New Microbes New Infect 7:48-49. 10.1016/j.nmni.2015.06.001

Greiner T, and Backhed F. 2011. Effects of the gut microbiota on obesity and glucose homeostasis. Trends Endocrinol Metab 22:117-123. 10.1016/j.tem.2011.01.002

Gurevich A, Saveliev V, Vyahhi N, and Tesler G. 2013. QUAST: quality assessment tool for genome assemblies. Bioinformatics 29:1072-1075.

Han I, Congeevaram S, Ki DW, Oh BT, and Park J. 2011. Bacterial community analysis of swine manure treated with autothermal thermophilic aerobic digestion. Appl Microbiol Biotechnol 89:835-842. 10.1007/s00253-010-2893-8

Kaakoush NO. 2015. Insights into the Role of Erysipelotrichaceae in the Human Host. Front Cell Infect Microbiol 5:84. 10.3389/fcimb.2015.00084

Kim M, Oh HS, Park SC, and Chun J. 2014. Towards a taxonomic coherence between average nucleotide identity and $16 \mathrm{~S}$ rRNA gene sequence similarity for species demarcation of prokaryotes. Int J Syst Evol Microbiol 64:346-351. 10.1099/ijs.0.059774-0

Kimura M. 1980. A simple method for estimating evolutionary rates of base substitutions through comparative studies of nucleotide sequences. J Mol Evol 16:111-120.

Kobyliak N, Conte C, Cammarota G, Haley AP, Styriak I, Gaspar L, Fusek J, Rodrigo L, and Kruzliak P. 2016. Probiotics in prevention and treatment of obesity: a critical view. Nutrition \& Metabolism 13:14. 10.1186/s12986-016-0067-0

Konstantinidis KT, and Tiedje JM. 2005. Towards a genome-based taxonomy for prokaryotes. J Bacteriol 187:6258-6264. 10.1128/JB.187.18.6258-6264.2005

Konstantinidis KT, and Tiedje JM. 2007. Prokaryotic taxonomy and phylogeny in the genomic era: advancements and challenges ahead. Curr Opin Microbiol 10:504-509. 10.1016/j.mib.2007.08.006

Kumar S, Stecher G, and Tamura K. 2016. MEGA7: Molecular Evolutionary Genetics Analysis Version 7.0 for Bigger Datasets. Mol Biol Evol 33:1870-1874. 10.1093/molbev/msw054

Lagier JC, Khelaifia S, Alou MT, Ndongo S, Dione N, Hugon P, Caputo A, Cadoret F, Traore SI, Seck EH, Dubourg G, Durand G, Mourembou G, Guilhot E, Togo A, Bellali S, Bachar D, Cassir N, Bittar F, Delerce J, Mailhe M, Ricaboni D, Bilen M, Dangui Nieko NP, Dia Badiane NM, Valles C, Mouelhi D, Diop K, Million M, Musso D, Abrahao J, Azhar El, Bibi F, Yasir M, Diallo A, Sokhna C, Djossou F, Vitton V, Robert C, Rolain JM, La Scola B, Fournier PE, Levasseur A, and Raoult D. 2016. Culture of previously uncultured members of the human gut microbiota by culturomics. Nat Microbiol 1:16203. 10.1038/nmicrobiol.2016.203

Lagier JC, Million M, Hugon P, Armougom F, and Raoult D. 2012. Human gut microbiota: repertoire and variations. Front Cell Infect Microbiol 2:136. 10.3389/fcimb.2012.00136

Lee I, Ouk Kim Y, Park SC, and Chun J. 2016. OrthoANI: An improved algorithm and software for calculating average nucleotide identity. Int J Syst Evol Microbiol 66:1100-1103. 10.1099/ijsem.0.000760

Meier-Kolthoff JP, and Goker M. 2019. TYGS is an automated high-throughput platform for state-of-theart genome-based taxonomy. Nat Commun 10:2182. 10.1038/s41467-019-10210-3

Rzhetsky. A., and M. N. 1992. A Simple Method for Estimating and Testing Minimum Evolution Trees MOl Biol Evol 9:945-967.

Saitou N, and Nei M. 1987. The neighbor-joining method: a new method for reconstructing phylogenetic trees. Mol Biol Evol 4:406-425. 10.1093/oxfordjournals.molbev.a040454

Sasser M. 1990. Identification of Bacteria by Gas Chromatography of Cellular Fatty Acids. MIDI Techincal Note 101. 
444

445

446

447

448

449

450

451

452

453

454

455

456

457

458

459

460

461

462

463

464

465

466

467

468

469

470

471

472

473

474

475

476

477

Seemann T. 2014. Prokka: rapid prokaryotic genome annotation. Bioinformatics 30:2068-2069. 10.1093/bioinformatics/btu153

Shields P, and Cathcart L. 2011

Motility Test Medium Protocol. American Society for Microbiology.

Tegtmeier D, Riese C, Geissinger O, Radek R, and Brune A. 2016. Breznakia blatticola gen. nov. sp. nov. and Breznakia pachnodae sp. nov., two fermenting bacteria isolated from insect guts, and emended description of the family Erysipelotrichaceae. Syst Appl Microbiol 39:319-329. 10.1016/j.syapm.2016.05.003

Verbarg S, Göker M, Scheuner C, Schumann P, and Stackebrandt E. 2014. The Families Erysipelotrichaceae emend., Coprobacillaceae fam. nov., and Turicibacteraceae fam. nov. In: Rosenberg E, DeLong EF, Lory S, Stackebrandt E, and Thompson F, eds. The Prokaryotes: Firmicutes and Tenericutes. Berlin, Heidelberg: Springer Berlin Heidelberg, 79-105.

Verbarg S, Rheims H, Emus S, Fruhling A, Kroppenstedt RM, Stackebrandt E, and Schumann P. 2004. Erysipelothrix inopinata sp. nov., isolated in the course of sterile filtration of vegetable peptone broth, and description of Erysipelotrichaceae fam. nov. Int I Syst Evol Microbiol 54:221-225. 10.1099/ijs.0.02898-0

Vetizou M, Pitt JM, Daillere R, Lepage P, Waldschmitt N, Flament C, Rusakiewicz S, Routy B, Roberti MP, Duong CP, Poirier-Colame V, Roux A, Becharef S, Formenti S, Golden E, Cording S, Eberl G, Schlitzer A, Ginhoux F, Mani S, Yamazaki T, Jacquelot N, Enot DP, Berard M, Nigou J, Opolon P, Eggermont A, Woerther PL, Chachaty E, Chaput N, Robert C, Mateus C, Kroemer G, Raoult D, Boneca IG, Carbonnel F, Chamaillard M, and Zitvogel L. 2015. Anticancer immunotherapy by CTLA-4 blockade relies on the gut microbiota. Science 350:1079-1084. 10.1126/science.aad1329 Weisburg WG, Tully JG, Rose DL, Petzel JP, Oyaizu H, Yang D, Mandelco L, Sechrest J, Lawrence TG, Van Etten J, Maniloff J, and Woese CR. 1989. A phylogenetic analysis of the Mycoplasmas: Basis for their classificiation. Journal of Bacteriology 171:6455-6467.

Yarza P, Yilmaz P, Pruesse E, Glöckner FO, Ludwig W, Schleifer K-H, Whitman WB, Euzéby J, Amann R, and Rosselló-Móra R. 2014. Uniting the classification of cultured and uncultured bacteria and archaea using 16S rRNA gene sequences. Nature Reviews Microbiology 12:635. 10.1038/nrmicro3330

https://www.nature.com/articles/nrmicro3330\#supplementary-information

Yutin N, and Galperin MY. 2013. A genomic update on clostridial phylogeny: Gram-negative spore formers and other misplaced clostridia. Environ Microbiol 15:2631-2641. 10.1111/14622920.12173 


\section{Table $\mathbf{1}$ (on next page)}

Table 1

Differential phenotypic features of the strain $\mathrm{SG}_{502}{ }^{\top}$ and its closest phylogenetic neighbor $C$. innocuum ATCC $14501^{\top}$ and E. dolichum DSM $3991^{\top}$ identified using API ZYM (bioMerieux, France). 
Table 1: Differential phenotypic features of the strain $S G 502^{\mathrm{T}}$ and its closest phylogenetic neighbor C. innocuum ATCC $14501^{\mathrm{T}}$ and E. dolichum DSM $3991^{\mathrm{T}}$ identified using API ZYM (bioMerieux, France).

\begin{tabular}{|c|c|c|c|}
\hline Characteristics & $\mathrm{SG} 502^{\mathrm{T}}$ & ATCC $14501^{\mathrm{T}}$ & $\operatorname{DSM} 3991^{\mathrm{T}}(\square)$ \\
\hline Cell shape & Spindle & Rods & Rods \\
\hline Gram stain & + & + & + \\
\hline Growth at $37^{\circ} \mathrm{C}$ (an.) & + & + & + \\
\hline Optimal pH & 7 & 7 & 7 \\
\hline Motility & - & - & - \\
\hline Size $(\mu)$ & $1.5 \times 0.35$ & $2.0-4.0 \times 0.4-1.0$ & $1.6-6.0 \times 0.4-0.6$ \\
\hline \multicolumn{4}{|l|}{ Carbon sources utilization } \\
\hline Glucose & + & + & + \\
\hline Sucrose & - & + & - \\
\hline Salicin & - & + & - \\
\hline Mannitol & - & + & - \\
\hline Lactose & - & - & - \\
\hline Sorbitol & + & - & - \\
\hline Maltose & + & \pm & + \\
\hline D-Trehalose & + & + & + \\
\hline Raffinose & - & + & - \\
\hline Cellobiose & + & + & - \\
\hline \multicolumn{4}{|l|}{ Enzyme activity (API ZYM) } \\
\hline Alkaline phosphatase & + & + & ND \\
\hline Esterase (C4) & - & - & ND \\
\hline Esterase Lipase (C8) & - & - & ND \\
\hline Lipase (C14) & - & - & ND \\
\hline Leucine arylamidase & - & + & ND \\
\hline Valine arylamidase & - & - & ND \\
\hline Cystine arylamidase & - & + & ND \\
\hline Trypsin & - & - & ND \\
\hline$\alpha$-chymotrypsin & - & + & ND \\
\hline Acid phosphatase & - & + & ND \\
\hline Naphthol-As-Bi-phosphopydrolase & - & - & ND \\
\hline$\alpha$-galactosidase & - & - & ND \\
\hline$\beta$-galactosidase & - & - & ND \\
\hline$\beta$-glucuronidase & - & - & ND \\
\hline$\alpha$-glucosidase & - & - & ND \\
\hline$\beta$-glucosidase & - & - & ND \\
\hline $\mathrm{N}$-acetyl- $\beta$-glucosaminidase & - & - & ND \\
\hline$\alpha$-mannosidase & - & - & ND \\
\hline
\end{tabular}


GC content $(\%)$

32.88

44.5

39

Data obtained from Moore et al (1976).

"ND" not determined.

1 


\section{Table 2 (on next page)}

Table 2

Cellular fatty acid contents percentages (\%) of strain $\mathrm{SG} 502^{\top}$ compared to its phylogenetic neighbors C. innocuum ATCC $14501^{\top}$ and E. dolichum DSM $3991^{\top}$. Those fatty acids which were not separated using MIDI system were considered as summed features. Summed feature 5 contains $\mathrm{C}_{15: 0}$ DMA or $\mathrm{C}_{14: 0} 3-\mathrm{OH}$; summed feature 8 contains $\mathrm{C}_{17: 1 \text { cis } 9}$ or $\mathrm{C}_{17: 2}$ and summed feature contains $\mathrm{C}_{18: 1} \mathrm{c} 11 / \mathrm{t} 9 / \mathrm{t} 6$ or UN17.83Q. 
Table 2: Cellular fatty acid contents percentages (\%) of strain SG502 compared to its phylogenetic neighbors C. innocuum ATCC $14501^{\mathrm{T}}$ and $E$. dolichum DSM 3991 ${ }^{\mathrm{T}}$. Those fatty acids which were not separated using MIDI system were considered as summed features. Summed feature 5 contains $\mathrm{C}_{15: 0}$ DMA or $\mathrm{C}_{14: 0} 3-\mathrm{OH}$; summed feature 8 contains $\mathrm{C}_{17: 1 \text { cis } 9}$ or $\mathrm{C}_{17: 2}$ and summed feature contains $\mathrm{C}_{18: 1} \mathrm{c} 11 / \mathrm{t} 9 / \mathrm{t} 6$ or UN17.83Q.

\begin{tabular}{|c|c|c|c|}
\hline Characteristics & SG502 ${ }^{\mathrm{T}}$ & ATCC $14501^{\mathrm{T}}$ & $\begin{array}{l}\text { DSM 3991 } \\
(\dagger)\end{array}$ \\
\hline \multicolumn{4}{|l|}{ Straight chain } \\
\hline $\mathrm{C}_{10: 0}$ & 0.31 & 0.32 & 1 \\
\hline $\mathrm{C}_{12: 0}$ & 1.74 & 3.28 & - \\
\hline $\mathrm{C}_{14: 0}$ & 3.54 & 8.85 & 1.6 \\
\hline $\mathrm{C}_{16: 0}$ & 14.7 & 23.7 & 22.8 \\
\hline $\mathrm{C}_{16: 0}$ aldehyde & 0.42 & 2.78 & - \\
\hline $\mathrm{C}_{17: 0}$ & 1.41 & - & 1.8 \\
\hline $\mathrm{C}_{18: 0}$ & 22.55 & 10.56 & 17.1 \\
\hline \multicolumn{4}{|c|}{ Dimethyl acetal (DMA) } \\
\hline $\mathrm{C}_{16: 0}$ DMA & 1.46 & 9.95 & - \\
\hline $\mathrm{C}_{18: 0}$ DMA & 3.62 & 2.83 & - \\
\hline \multicolumn{4}{|l|}{ Unsaturated } \\
\hline $\mathrm{C}_{16: 1} \omega 9 \mathrm{c}$ & 0.99 & 6.51 & - \\
\hline $\mathrm{C}_{16: 1} \omega 7 \mathrm{c}$ & 6.47 & 10.59 & - \\
\hline $\mathrm{C}_{18: 1} \omega 9 \mathrm{c}$ & 29.82 & 14.64 & 33.9 \\
\hline $\mathrm{C}_{18: 1} \omega 7 \mathrm{c}$ & 10.77 & 3.08 & - \\
\hline Summed Feature 8 & 0.54 & - & - \\
\hline Summed Feature 10 & 10.77 & 3.08 & - \\
\hline
\end{tabular}

(¥) Data from Paek et al. 2017 (Paek et al. 2017) 


\section{Table 3(on next page)}

Table 3

Genomic comparison of the strain $\mathrm{SG} 502^{\top}$ with its neighbors 
1 Table 3: Genomic comparison of the strain SG502 ${ }^{\mathrm{T}}$ with its neighbors.

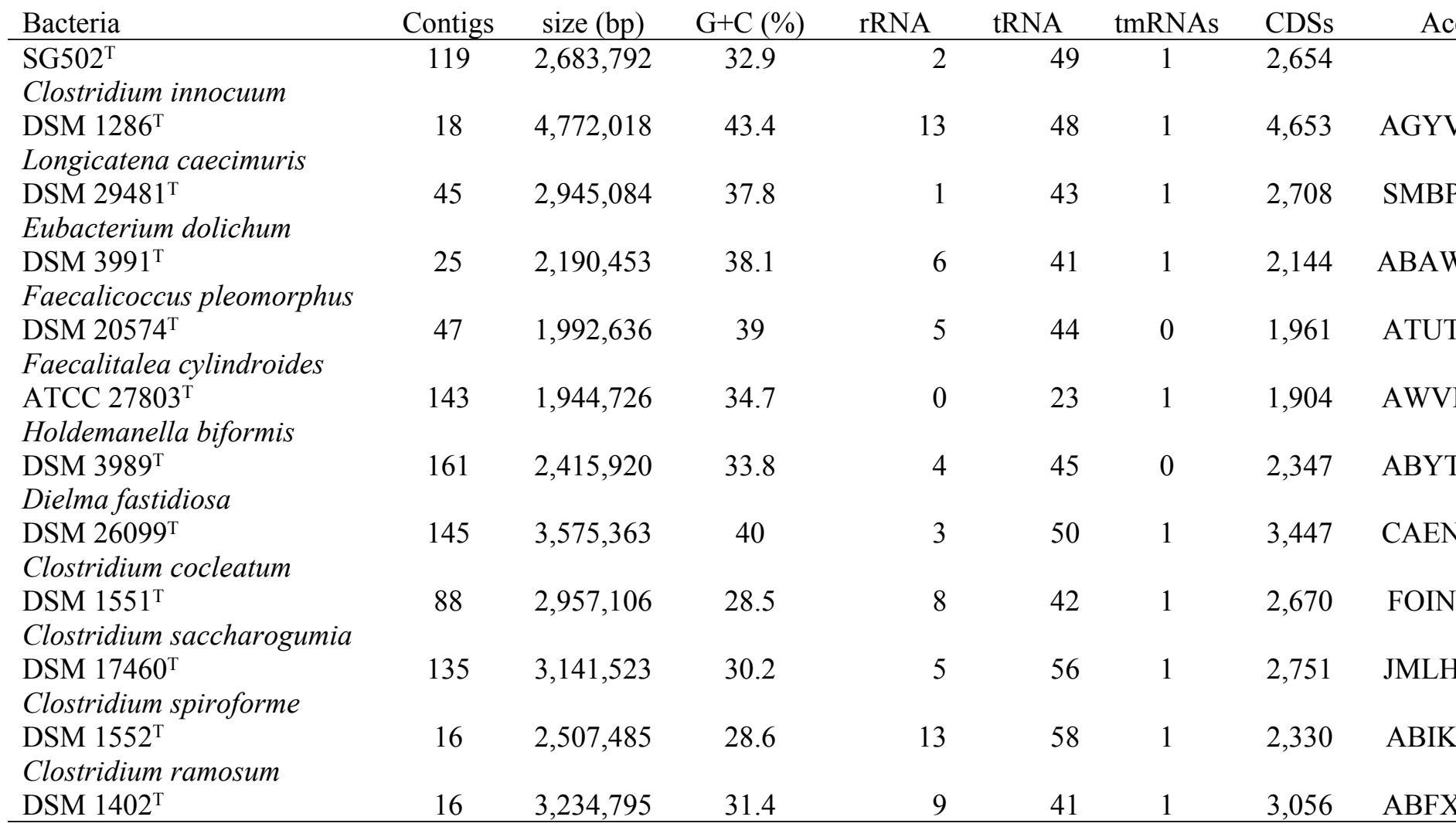

2 


\section{Table 4 (on next page)}

\section{Table 4}

Genomic comparison of the strain SG502 ${ }^{\top}$ with its neighbors $16 \mathrm{~S}$ rRNA phylogenetic neighbors and proposed Erysipelatoclostridium members using TYGS 
1 Table 4: Genomic comparison of the strain SG502 ${ }^{\mathrm{T}}$ with its neighbors $16 \mathrm{~S}$ rRNA phylogenetic

2 neighbors and proposed Erysipelatoclostridium members using TYGS.

\begin{tabular}{|c|c|c|c|}
\hline Bacteria & $\begin{array}{c}\text { dDDH } \\
(\mathrm{d} 4, \%)\end{array}$ & $\begin{array}{c}\text { C.I. } \\
(\mathrm{d} 4, \%)\end{array}$ & $\begin{array}{c}\mathrm{G}+\mathrm{C} \text { difference } \\
(\%)\end{array}$ \\
\hline Clostridium innocuum DSM $1286^{\mathrm{T}}$ & 19.8 & {$[17.6-22.2]$} & 10.48 \\
\hline Longicatena caecimuris DSM $29481^{\mathrm{T}}$ & 20.5 & [18.3 - 22.9] & 4.86 \\
\hline Eubacterium dolichum DSM $3991^{\mathrm{T}}$ & 20.6 & {$[18.4-23.0]$} & 5.22 \\
\hline Faecalicoccus pleomorphus DSM $20574^{\mathrm{T}}$ & 19.6 & {$[17.4-22.0]$} & 6.14 \\
\hline Faecalitalea cylindroides ATCC $27803^{\mathrm{T}}$ & 18.9 & {$[16.7-21.3]$} & 1.79 \\
\hline Holdemanella biformis DSM 3989 ${ }^{\mathrm{T}}$ & 19 & {$[16.8-21.4]$} & 0.9 \\
\hline Dielma fastidiosa DSM 26099 & 20.1 & {$[17.9-22.5]$} & 7.08 \\
\hline Clostridium cocleatum DSM $1551^{\mathrm{T}}$ & 23.5 & {$[21.2-26.0]$} & 4.37 \\
\hline Clostridium saccharogumia DSM $17460^{\mathrm{T}}$ & 18.6 & {$[16.4-21.0]$} & 2.72 \\
\hline Clostridium spiroforme DSM $1552^{\mathrm{T}}$ & 19.8 & {$[17.6-22.2]$} & 4.31 \\
\hline Clostridium ramosum DSM 1402 & 22.4 & {$[20.1-24.8]$} & 1.5 \\
\hline
\end{tabular}

3 


\section{Figure 1}

Figure 1

A. MALDI-ToF reference spectrum obtained for $\mathrm{SG} 02^{\top}$. B. Scanning electron micrograph of strain $\mathrm{SG} 502^{\top}$. Cells were imaged after culturing in anaerobic conditions for 24 hours at $37^{\circ} \mathrm{C}$ in BHI-M medium. Bar, $200 \mathrm{~nm}$.

A

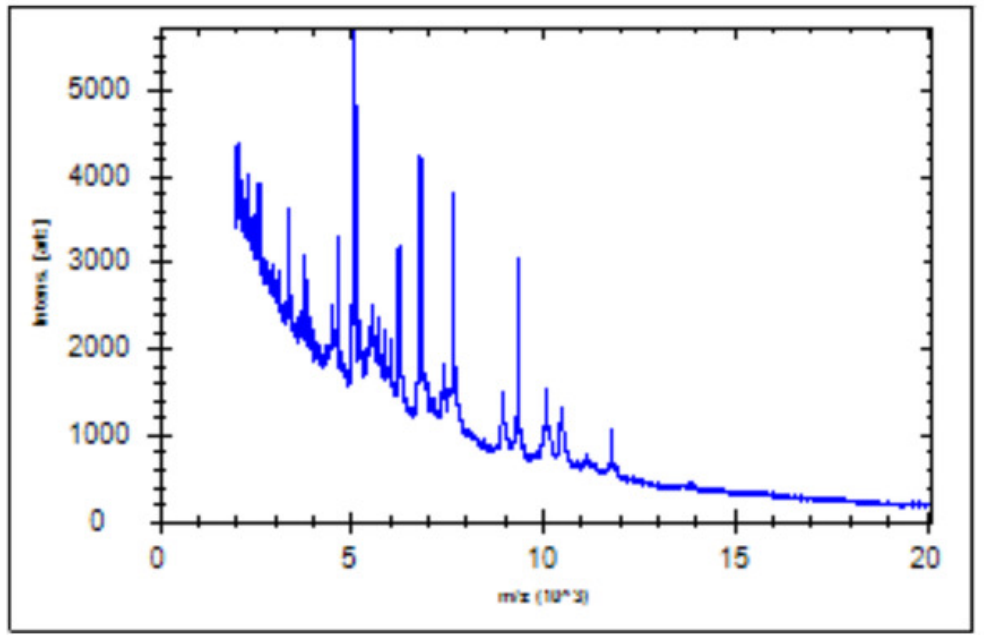

$\mathrm{B}$

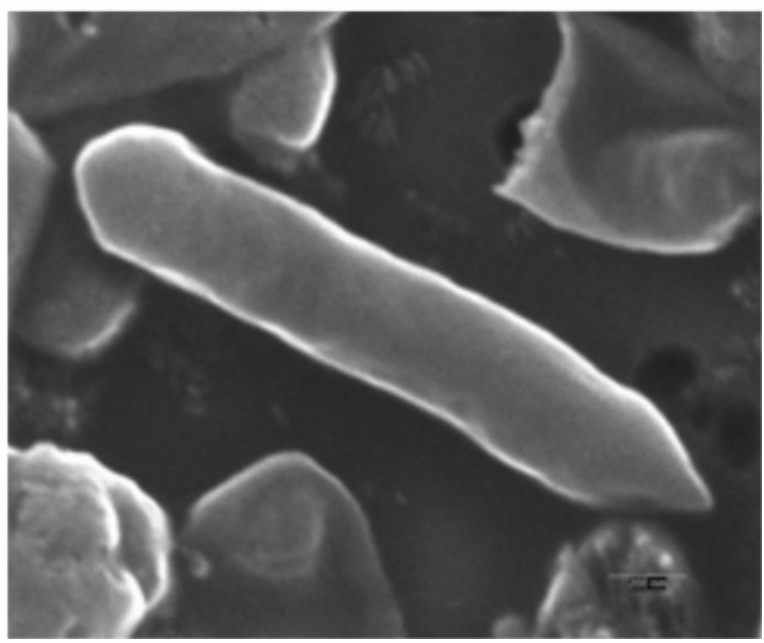




\section{Figure 2}

Figure 2

Neighbor Joining tree of $16 \mathrm{~S}$ rRNA gene sequences of $\mathrm{SG}^{\mathrm{N}} 02^{\top}$ with related species under Erysipelotrichaceae family. GenBank accession numbers of the 16S rRNA gene sequences are given in parentheses. The sequences were aligned using MUSCLE (Edgar 2004) and the evolutionary distances were computed using Kimura 2-parameter method to obtain the phylogenetic tree in MEGAX (Kumar et al. 2018) after 1000 bootstrap tests (shown as percentages with associated taxa clustered together next to the branches. The tree is drawn to scale, with branch lengths measured in the number of substitutions per site. Bar, 0.05 substitutions per nucleotide position. Clostridium butyricum ATCC $19398^{\top}$ was used as an outgroup. 


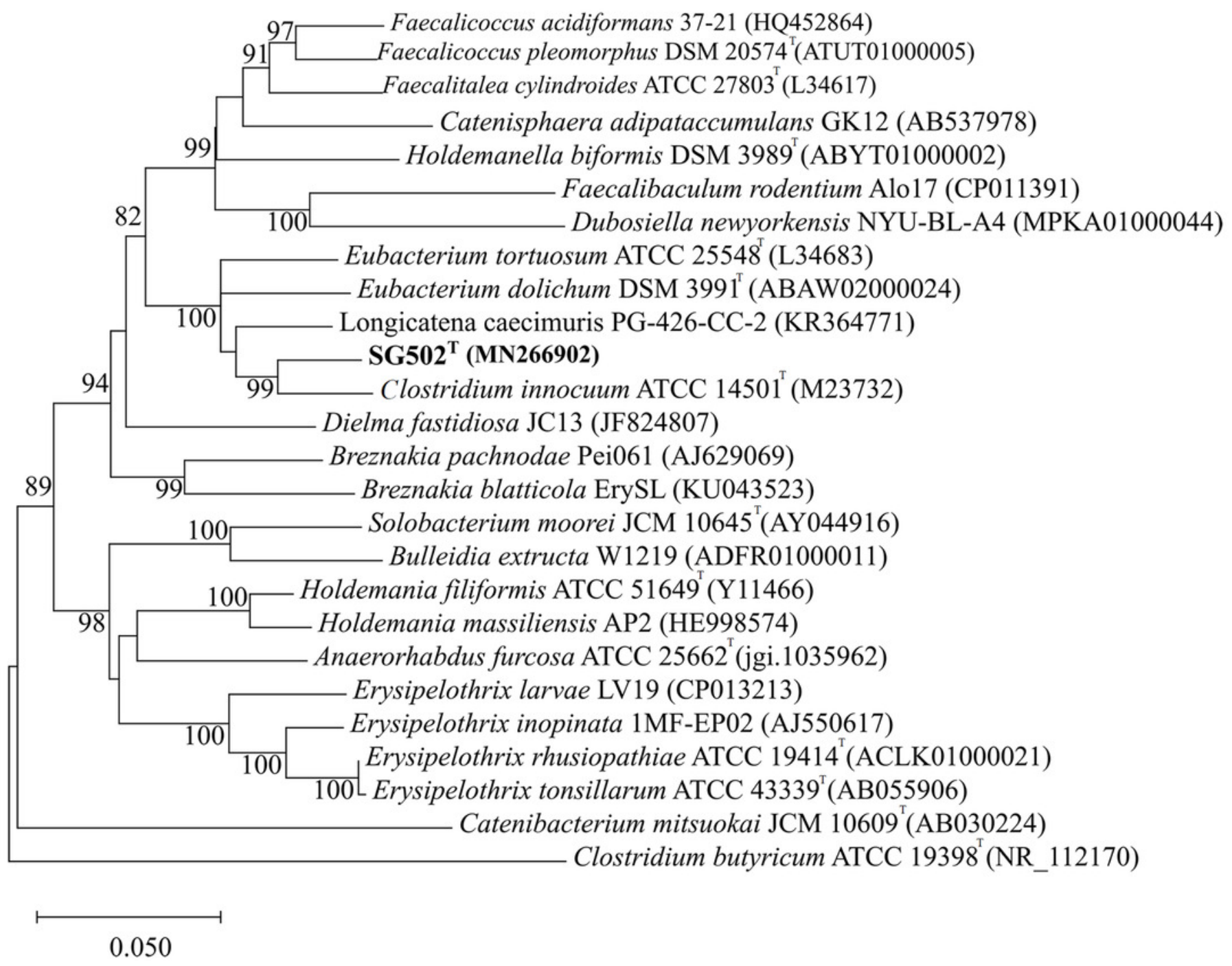




\section{Figure 3}

Figure 3

Circular visualization of genome of $\mathbf{S G 5 0 2}^{\mathbf{T}}$. From outside to inside, "green" circle represents total number of CDS, "blue" represents number of CDS in positive strand, "bluish green" represents number of CDS in negative strand and "red" represents tRNAs position in the genome. The innermost circle represents GC skewness and circle inside to tRNAs represent average GC content. "Magenta” color represents GC at lower level while "Olive green" color represents GC at higher level. 


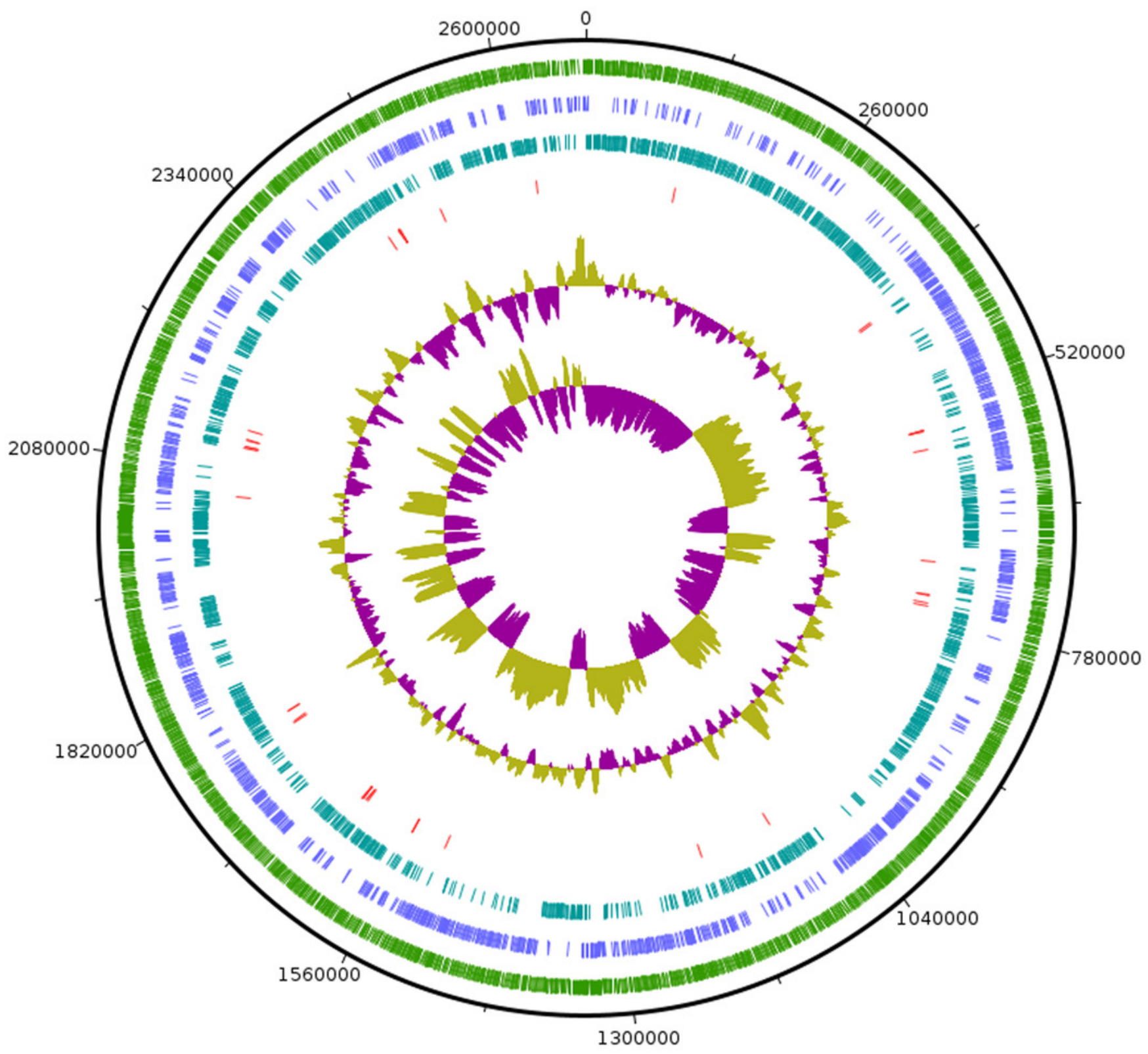


Figure 4

Figure 4

\section{Genomic comparison of SG502 ${ }^{\top}$ genome with its neighbors using OrthoANI in OAT}

software. A. Comparison with $16 \mathrm{~S}$ phylogenetic neighbors B. Comparison with formerly proposed members of genus Erysipelatoclostridium. Color scale indicates \% identity between the genomes.

A

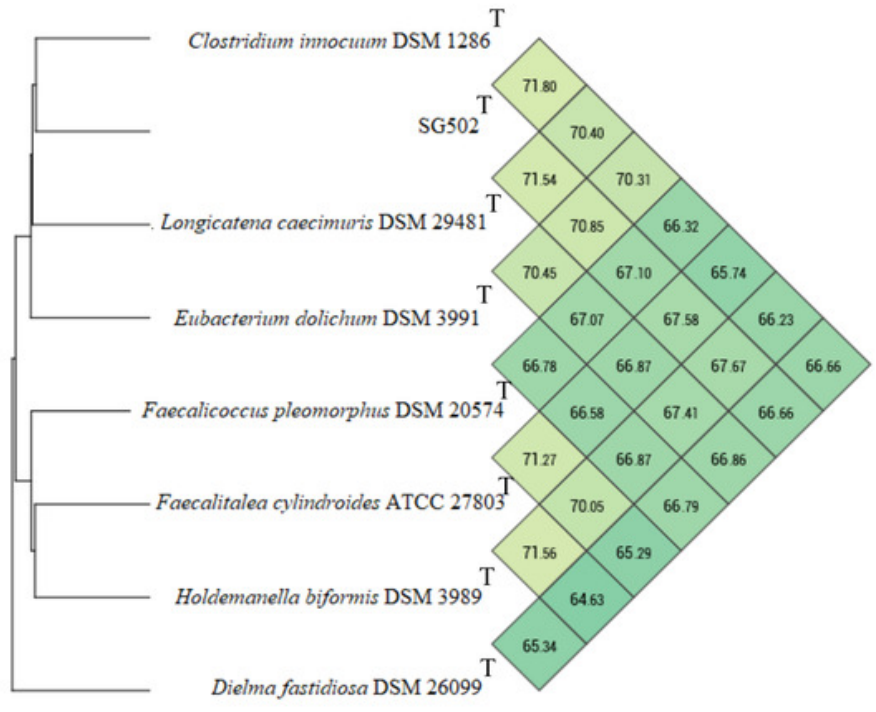

B 100

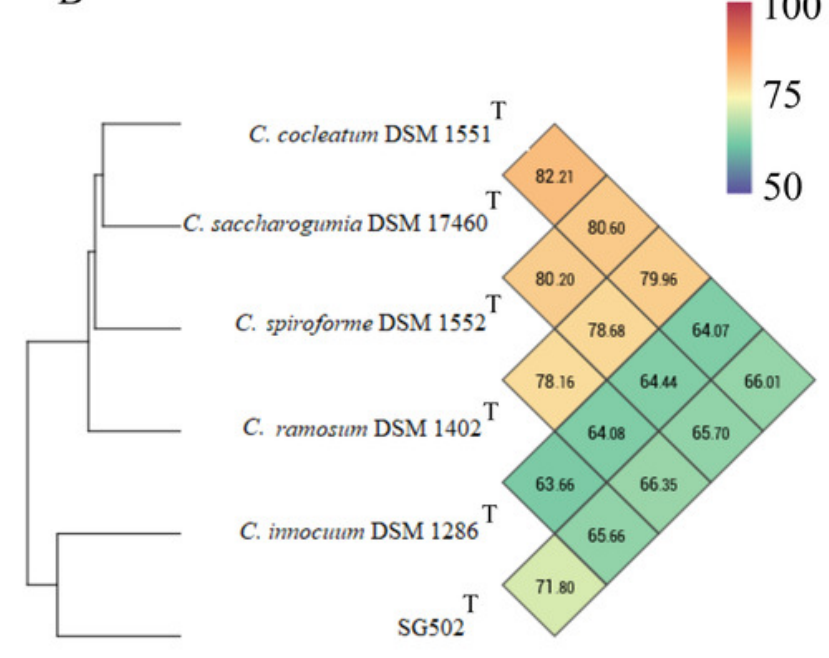




\section{Figure 5}

Figure 5

Average Amino acid composition comparison of the strain SG502 ${ }^{\top}$ with its neighbors $16 \mathrm{~S}$ rRNA phylogenetic neighbors and proposed Erysipelatoclostridium members using AAI calculator 


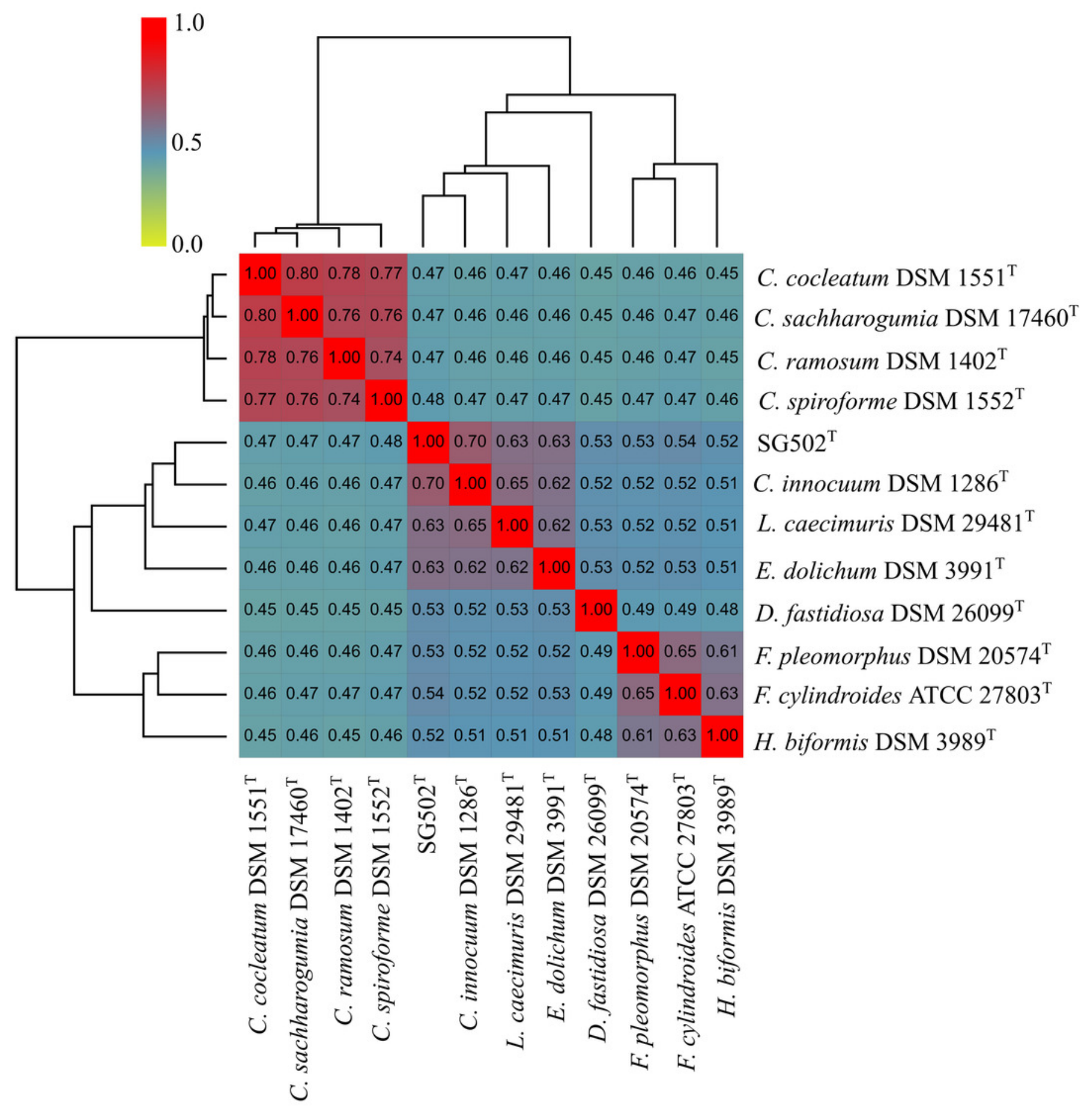

